record of his life is his own "Reminiscences of an Astronomer", published when he was sixty-eight years of age. In this, when speaking of Cayley the mathematician, he said, "His life was that of a man moved to investigation by an uncontrollable impulse; the only sort of man whose work is destined to be imperishable". The remark might well apply to Newcomb himself, for when at the age of twenty-two years, after an unusual start in life-which had included two years' service under a quack doctor-he entered his own "world of sweetness and light" as a computer in the office of the "Nautical Almanac" at Cambridge, Mass., his genius found the avenue which was to lead him to the highest distinction.

Of his work, his travels and his friendships of the years 1857-77, Newcomb gave an account in the early chapters in his "Reminiscences": "On September 15, 1877," he went on to say, "I took charge of the Nautical Almanac Office. The change was one of the happiest in my life. I was now in a position of recognised responsibility, where my recommendations met with the respect due to that responsibility, where I could make plans with the assurance of being able to carry them out. ..." He was editor of the "American Ephemeris and Nautical Almanac" for twenty years, and his most valuable work for science was done in connexion with it. It was this work which led to his being awarded the Copley Medal in 1890, and being elected a foreign associate of the Paris Academy of Sciences in 1895, in succession to Helmholtz.

A devoted public servant and an indefatigable worker, Newcomb set an inspiring example to all with whom he came in contact, while, said Sir Robert Ball, "His habitual loftiness of thought, nobility of character, dignified courtesy and everready helpfulness endeared him to his many friends on both sides of the Atlantic".
Schiaparelli was far more fortunate than Newcomb in his early environment, and at the age of nineteen years graduated from the University of Turin in engineering and architecture. For a year or two he taught mathematics, but astronomy had already laid its hold upon him, and in the year that Newcomb began his work at Cambridge, Schiaparelli was able to enter the Berlin Observatory, then directed by Encke, and two years later secured a post at Pulkovo under the Struves. Recalled to Italy in 1860 to become assistant to Carlini at the Brera Observatory, Milan, in September 1862 on the death of Carlini he was made director of the Observatory and this post he held for thirty-eight years.

Schiaparelli's first year at Milan was marked by his discovery of the asteroid Hesperia. Four years after becoming the director, he announced his discovery of the connexion between meteors and comets, and in 1873 he published his "Le Stelle Cadenti", declared by Lockyer to be one of the greatest contributions to the astronomical literature of the nineteenth century. In 1877 he commenced his observations of Mars, in 1882 began the study of Mercury and Venus and between 1875 and 1899 made 11,000 measures of double stars. Failing sight brought an end to his observations, and in 1900 he retired. Among his later work was his book on the astronomy of the Old Testament, in the preparation of which he had examined the dates of 2,764 Babylonian documents which had been translated.

Schiaparelli's views on the so-called 'canals' on Mars led to much controversy, and it is worth recalling that it was this which reawakened Lowell's interest in astronomy and led him to erect the Lowell Observatory, at Flagstaff, Arizona, where just five years ago the planet Pluto was discovered.

\title{
Modern Plastics
}

GOME criticism has been made of the word $S$ 'plastics' as applied to the industry which goes under this name to-day. The word 'plastics' is usually associated with clay, putty or similar materials which can be worked and shaped by hand. But 'plastics' has not, even in the past, been limited to materials which retain their plasticity. Clay, having been moulded into shape while in a plastic condition, takes permanent form after baking, but the article in its permanent form is still classified in the 'plastics' group. The bulk of the products of the plastics industry in its modern form may similarly be characterisedinitially plastic, they are converted by heat and pressure into permanent forms.
Bayer in 1872 first announced that phenols would react chemically with formaldehyde, but beyond this fact little further attention was paid by him to the product. Other workers investigated the reaction later, and Kleeberg in 1890 first discovered that it was not a pure product that was obtained, but a sticky viscous material. Then technical men more commercially minded came into the field and started investigations. One of the early patents was taken out by Luft in 1902, who described a horn-like material which could be turned and shaped into various articles. $\mathrm{He}$ described it as artificial horn. Others followed, but none of them appears to have made a material which was commercially useful, since they found 
no means of controlling the reaction or arriving at a reliable or satisfactory end-product.

Certain firms in Great Britain and in the United States began to develop the condensation product in liquid form for varnish purposes, but not until Dr. Baekeland turned his attention to this reaction was progress made. Dr. Baekeland announced his new discovery in 1908, and applied for patents in most countries in the world. The basis of his invention consisted in the use of relatively small proportions of ammonia as an accelerator in the reaction between phenol and formaldehyde, as against large amounts of acid or alkali used hitherto. He found that by the use of a small amount of alkali, the reaction could be controlled and checked at a convenient point during its progress, this resulting in an intermediate product between the raw materials and the final endproduct obtained previously, which was hard, brittle and non-plastic.

All previous workers on this product had obtained a crystalline product or a hardened mass which was of little value. Dr. Baekeland succeeded in producing a material which could be used commercially. It could be readily handled, being a resin-like solid which could be ground, powdered, softened or dissolved in solvents. This he termed Bakelite 'A'. This product was chemically changed on the application of heat by polymerisation into a permanently hard amber-like solid which would no longer soften by heat, had good insulating properties and was termed Bakelite ' $C$ '. When mixed with fillers in a powdered state, it could he introduced into steel moulds, subjected to heat and pressure in hydraulic presses, and, by continued application of heat, it set solid and assumed the shape or the contour of the mould into which it had been pressed, and could be discharged permanently solid. This process is the basis of the modern plastic moulding industry to-day.

The early material of Dr. Baekeland's invention was somewhat variable in quality and slow in its rate of hardening in the mould to the ' $\mathrm{C}$ ' stage, and consequently the moulding industry made slow headway. It was in a very elementary stage, and it was not until towards the end of the War that practical advancement in the technique of manufacture of what are now termed the resinoid moulding powders, showed any progress in Great Britain. The last fifteen years bas brought about considerable change in the industry and its technique. Where twenty-five years ago the moulding materials consisted of the resin A, ground to powder and mixed with dye and woodmeal, of which the rate of hardening was 5-15 minutes for an article of relatively small size, to-day similar articles are turned out from complex moulding mixtures at the rate of $1-1 \frac{1}{2}$ minutes in multiple impression moulds having as many as 50-75 impressions; so that where one article was produced in five minutes, we have to-day 200-250 of the same articles turned out in the same time.

The production of mouldings has been referred to as illustrating the advancement of one side of the resinoid plastics industry. Dr. Baekeland's invention led to the production of other useful materials, apart from mouldings for the electrical and allied industries. It was found that, when this Bakelite Resinoid A was dissolved in solvents, and paper sheets were impregnated with it and then dried and pressed together in a hydraulic press between steam-heated platens, the resinoid hardened and made a compact mass consisting of laminations of paper sealed together by the hardened resinoid; the product was 'Bakelite laminated sheets'. This material was found to be very hard and tough, yet it could be machined and had excellent insulating properties. It found a ready application in the electrical industry. The advancement in this branch of the industry has been less spectacular than in the moulding section, but advances have been made. The methods employed in production to-day are very much the same as when this material was originally introduced, apart from minor improvements in plant, but I feel sure we can look for great advances in methods of production, cheapening in costs and widening its applications.

Until the last year or two, the production of mouldings had been confined to small articles chiefly for the electrical industry, such as switch cover plates, distributor heads for car ignition sets and picnic set requisites and many similar products. With the introduction of radio sets at a price to attract the masses, the question of the production of cabinets to house the sets was considered by those concerns which turned their attention to the production of such sets in large quantities in standard and uniform design. It then became evident that a case or housing for such sets could be produced in plastics more fitting in design to meet modern requirements at prices to compete with those constructed of wood. This led to the production of the moulded radio cabinet, of which there are many examples to be seen to-day. The production of these cabinets called for the installation of very large and expensive hydraulic presses and moulds costing several thousands of pounds. The very existence of these presses will, no doubt, have the effect of leading the industry into the production of larger mouldings. The general tendency will be towards the production of still larger articles in moulded plastics, each moulding requiring many pounds of powder, thus gradually supplanting many articles and parts of articles at present made in wood or metal by plastic 
moulded articles made on mass production lines. When this comes about, it is obvious that designs will have to change to meet the modern technique of production.

Very serious artistic thought should be given to the designs for the future, in order that such production may not only be practical from a mass production point of view, but also both restful and pleasing to the eye in outline and colour. In that way they will establish for themselves a permanent future and not be just a 'five minute wonder' to die out for lack of permanent artistic foundation. This is a point to which the industry should pay attention if it desires to establish itself as one of the main industries of the future.

The laminated material referred to above is at present relatively new compared with the moulding industry. Its chief applications have been industrial, in so far that it has formed a part in a main assembly, that is, in its use for insulation purposes in electrical equipment. Now, however, the material can be produced in sheets of larger sizes and in various colours and finishes, and it is already finding a use in industries that cater for domestic requirements. The laminated sheet material has some valuable features as it is resistant to heat, not readily marked or scratched, unaffected by alcohol and other solvents, and can be highly polished. Such properties are of value for many domestic applications. It is used for tops of tables in cafés, for dressing-table tops in hotels. In the United States it has been tried out as panelling for ships, state-rooms, cocktail bars; and similar applications are under trial in Great Britain. There are many uses for this material not yet developed, as it is difficult to find any other class of product which exhibits similar properties. There is no doubt that we shall see large developments in its use during the next few years. When sheets of this product are available in pleasing soft colours, they are likely to find favour for room decoration, for which, in many ways, they are ideal.

Future designs will require careful thought and planning. Present ideas do not entirely fit in with production of this type of material, and a new art and technique will have to be developed to meet these new products. Many articles which were previously made by hand, in many cases elaborately decorated by the craftsman, will in the future be produced in mass by this new process of moulding and fashioning. For a time, the craftsman's hand on the finished article will disappear until the industry has so advanced its technique that present difficulties of production have disappeared; then, there will be room for the craftsman to exercise his art-not on the finished article or on its construction, but in the steel or other material forming the master model from which such articles will be produced, and by engraving into it pleasing designs and artistic ideas which will be effectively and correctly reproduced in detail on the moulded articles. By these modern processes, such articles will be manufactured in quantities which will enable them to be sold at prices within the purchasing capacity of the majority.

H. V. Potter.

\section{O bitu a ry}

\section{Dr. R. C. KNIGHT}

CCIENTIFIC horticulture has suffered a heavy loss $D$ by the death on January 28 of Dr. R. C. Knight, assistant director of the East Malling Research Station. He was born in 1891 and was educated at Sexey's School, Bruton, Somerset, and at the University of Bristol, where he took a degree in botany. He obtained a Board of Agriculture research scholar. ship in plant physiology in 1916, which he held at the Imperial College of Science and Technology, and in $\mathbf{1 9 1 9}$ he was appointed to the staff of the Research Institute of Plant Physiology of that College. His association with East Malling Research Station began in 1920, when the demonstration of striking examples of rootstock influence upon the scion opened up a promising field for physiological investigations. At first Dr. Knight merely visited the Station for short periods to familiarise himself with his problems and to collect the necessary material. By 1922 it became obvious that in order to push forward with the work he must live on the spot with his material, and he was seconded for duty at the East Malling Station, where he worked until his death.
So wide were Knight's interests that he rapidly became familiar with the horticultural problems being investigated around him, and although he often said that these early years were "spent in closing doors by obtaining negative results rather than in opening them", this was an essential preliminary exploration, and he was all the time evolving in his mind and discussing with his colleagues those 'physio-pomological' methods which he used so much in later years. While he did much careful work in determining the optimum conditions for raising hard-wood and soft-wood cuttings, his outstanding contribution was concerned with the practice of layering. Here he emphasised and elucidated the all-important part played by the etiolation of the base of the shoot in encouraging adventitious rooting. By directing attention to this aspect he made it possible to reproduce with much greater certainty clonal races of a far wider range of plants than had been possible heretofore.

Knight's contribution to horticultural science, how ever, is in no way measured by the twentyor more pub. lished reports standing under his name. He exercised 